\title{
Research on the preparation and mechanical properties of biomedical metallic materials
}

\author{
Yukun Wei ${ }^{1, a}$, Haobo Zhang ${ }^{1, b}$, Xiao Jijun ${ }^{1, c}$, Yang Qiao ${ }^{1, d^{*}}$ \\ ${ }^{1}$ School of Mechanical Engineering, University of Jinan, Jinan, Shandong 250000, China

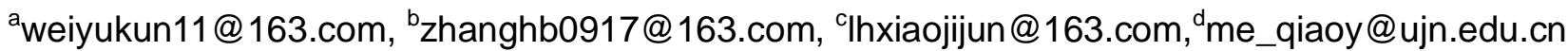

Keywords: biomedical metallic materials; preparation; mechanical properties

Abstract. This paper summarized the preparation and mechanical properties of current biomedical metallic materials, which contained medical stainless steel, titanium based alloy, magnesium alloy. Preparation covered metal smelting, powder metallurgy and micro-arc oxidation technology. The mechanical properties included the factors need to be focused on as implant: yield strength, modulus of elasticity and corrosion resistance.

\section{Introduction}

As the longest used biological material, metal material has good mechanical properties, so it has widely applied as implants, orthopedic implants and stent, dental, and cardiovascular therapeutic areas. Currently, biomedical metallic materials of clinical application includes stainless steel, titanium based alloy and magnesium alloy. Titanium alloy receives a lot of attention as it has appropriate mechanical properties, smaller density, excellent biocompatibility and resistance to corrosion[1-3]. The modulus of elasticity of magnesium alloys is similar to the bone, which can effectively avoid stress shielding, and the alloy's degradation in vivo avoids secondary damage caused by the implant removed. Therefore, magnesium alloy and titanium alloys become the most popular researched biomedical metallic materials.

\section{Stainless steel}

Preparation and mechanical properties. Stainless steel has been widely used in a variety of manufacturing of medical devices and surgical tools because of its excellent mechanical properties, corrosion resistance and processing properties. The most commonly used material of stainless steel is 316L. But 316L stainless steel will release the nickel ion in the course, which is considered to be toxic elements and can cause allergic reactions and cancer. In recent years, some scholars have studied the biomedical nickel-free austenitic stainless steel with high nitrogen. Compared with the traditional 316L stainless steel, this stainless steel not only to ensure no harmful substances-nickel ions-will precipitate, but also to increase the strength and maintain a high toughness and ductility at the same time[4].

Currently, the methods of the preparation of nickel-free austenitic stainless steel with high nitrogen consist hot isostatic melting, pressurized induction furnace, powder metallurgy and high-temperature nitriding. The suitable way for industrial mass production is pressurized ESR techniques, but there are still issues as nitrogen distributes unevenly. In recent years, the preparation technique of using high-temperature solid-phase nitriding process for preparing small size nickel-free austenitic stainless steel with high nitrogen has been focused on. By vacuum induction melting (VIM) and remelting (ESR) (double-smelting process for smelting) then rolling and forging, the nickel-free austenitic stainless steel with different nitrogen content (respectively 
$0.50 \%, 0.56 \%$ and $0.62 \%$ )is prepared. The prepared material is cut into a diameter of $15 \mathrm{~mm}$, a thickness is $2 \mathrm{~mm}$ wafer, to which the tests of impact properties and tensile properties are performed[5]. Table 1 shows the parameters of mechanical properties of the different nitrogen content stainless steel after the performance test. Nickel-free austenitic stainless steel with high nitrogen is not only to meet the basic mechanical properties of $316 \mathrm{~L}$ stainless steel, but also to ensure a single austenite and no harmful elements nickel exist[6].

Table 1 Mechanical properties of biomedical nickel-free austenitic stainless steel with high nitrogen[5]

\begin{tabular}{ccccc}
\hline Material & $\begin{array}{c}\text { Tensile strength } \\
R_{\mathrm{m}}(\mathrm{MPa})\end{array}$ & $\begin{array}{c}\text { Yield strength } \\
R_{\mathrm{p}}(\mathrm{MPa})\end{array}$ & $\begin{array}{c}\text { Plasticity index } \\
\text { Elongation A(\%) }\end{array}$ & $\begin{array}{c}\text { Reduction of } \\
\text { area Z(\%) }\end{array}$ \\
\hline 17Cr15Mn2Mo0.5N & 1159 & 964 & 34 & 72.5 \\
$17 \mathrm{Cr} 15 \mathrm{Mn} 2 \mathrm{Mo} 0.56 \mathrm{~N}$ & 1196 & 1010 & 29 & 69.5 \\
$17 \mathrm{Cr} 15 \mathrm{Mn} 2 \mathrm{Mo} 0.62 \mathrm{~N}$ & 1231 & 1071 & 26 & 60 \\
316L & 480 & 177 & 40 & 60 \\
\hline
\end{tabular}

Problems and deficiencies. Although medical austenitic stainless steel implants has excellent overall performance, there are still some unavoidable problems and deficiencies in the long-term of clinical use. Firstly, the characteristics that the high density ( about $7.8 \mathrm{~g} / \mathrm{cm}^{3}$ ), high strength (300 to $1000 \mathrm{MPa}$ ) and high elastic modulus (about 200GPa) have large difference from the mechanical properties of bone, that leads to the mismatch capacitively, causing stress shielding, bone osteoporosis, bone resorption or bone atrophy phenomenon. Due to the lack of sufficient mechanical stress stimulation bone tissue can't form callus at the fracture site easily, leading to secondary fractures easily. Secondly, the biological environment will cause corrosion or abrasion to medical stainless steel, the phenomenon may be worse as stainless steel in the human body biologically inert surface without biological activity. And later the combination between the implant and surrounding body tissue becomes loose easily, affecting therapeutic effect.

\section{Titanium based alloy}

Compared with biological stainless steel, titanium based alloy will reduce the burden on the human body after implanting into the human body as the less dense. The modulus of elasticity of titanium alloy is low and close to the human skeleton. That will reduce the stress shielding phenomenon caused by the mismatch on mechanical properties. Titanium alloy won't do harm to human body as it is non-toxic.

Porous Ti-Ni alloy. Ti-Ni alloy with equivalent atomic ratio has not only a similar super-elastic with human bone tissue, but also a special shape memory effect, wear and corrosion resistance and biocompatibility, which are expected to make Ti-Ni alloy an excellent bone substitute material. Ways of preparation of porous Ti-Ni alloy include conventional powder sintering method, SHS (Self-propagating High-temperature Synthesis), hot isostatic pressing, rapid prototyping technology, template impregnation, vacuum sintering method[7].

High-purity titanium and nickle powder were selected as raw elements, and they were prepared in a ratio of 1:1. It is unnecessary to add any forming agent as the powder has good formability. Powders were uniformly mixed by ball milling drum, molded after mixing for $4 \mathrm{~h}$ (molding pressure: $300 \mathrm{MPa}$, sintering temperature: $900^{\circ} \mathrm{C} \sim 1150^{\circ} \mathrm{C}$, insulating time: $4 \mathrm{~h}$, sintering vacuum: $\left.2.0 \times 10^{-2} \mathrm{~Pa}\right)$.

There is significant difference between porous and dense Ti-Ni alloy in the structure, so as in the behavior. Table 2 shows the mechanical properties of porous and dense Ti-Ni alloy. The elastic 
modulus of porous Ti-Ni alloy an order of magnitude lower than that of dense Ti-Ni alloy is more similar to bone tissue. While the strength of the porous alloy is much lower than the dense alloy, but it can well meet the requirements of bone strength. However, due to the presence of large specific surface area, good surface corrosion resistance and biocompatibility are very important for the porous structure alloys. At present, a large number of in vitro and in vivo clinical trials showed that the porous Ti-Ni alloy has body acceptable biocompatibility.

Table 2 Mechanical properties of porous Ti-Ni alloy and dense alloy[7]

\begin{tabular}{ccc}
\hline Properties & Porous Ti-Ni alloy & Dense Ti-Ni alloy \\
\hline Ultimate Strength/MPa & $200 \sim 1000$ & $700 \sim 1000$ \\
Yield Strength/MPa & $5 \sim 200$ & $250 \sim 800$ \\
Relative Elongation/\% & $1 \sim 20$ & $10 \sim 25$ \\
Recoverable & $1 \sim 10$ & $8 \sim 10$ \\
Deformation/\% & $4 \sim 90$ & $95 \sim 100$ \\
Shape Recovery/\% & $\leq 400$ & $400 \sim 600$ \\
Restoring Force $/ \mathrm{MPa}$ & $-200 \sim 150$ & $-200 \sim 110$ \\
Deformation & & \\
Temperature Range $/{ }^{\circ} \mathrm{C}$ &
\end{tabular}

Ti-Ag alloy. Ag improves the strength, the hardness and wear resistance of titanium alloy by solid solution strengthening. Ag can promote the rapid formation of stable titanium surface passivation film, to improve the corrosion resistance properties of titanium alloy. Thus the introduction of $\mathrm{Ag}$ to porous titanium based metal materials, will improve the mechanical properties, corrosion resistance and biological properties of porous titanium-based materials. Ag has a bactericidal function and trace amounts of $\mathrm{Ag}$ is completely harmless to humans, so introducing $\mathrm{Ag}$ into the porous titanium based metal materials will reduce infection caused by porous titanium based implant[8].

\section{Magnesium based alloy}

Magnesium and magnesium alloy are favored by more and more researchers as they have similar mechanical properties to human bone, biodegradability and biocompatible corrosion product characteristics. However, high degradation rate of magnesium in the physiological environment severely limits its clinical application. Therefore, alloyed ways is usually taken to improve alloy composition and structure, in order to improve the mechanical properties and corrosion resistance of magnesium alloy.

Mg-5wt\%Zn-0.1wt\%Sr alloy. It is prepared with high purity magnesium ingots, zinc particles and $\mathrm{Mg}-\mathrm{Sr}$ master alloys as raw materials. Smelting equipment consists three parts, melting furnace, distribution equipment and protective gas pouring mold. Grinding material to remove the surface oxide film, putting material into the crucible to preheat, the preheating temperature is $250^{\circ} \mathrm{C}$. When the furnace temperature was raised to $650^{\circ} \mathrm{C}$, put first preheated ingot into a graphite crucible, vacuumed and full with protective gas $\mathrm{SF}_{6}$. Heating for about $20 \mathrm{~min}$ at $750 \sim 800^{\circ} \mathrm{C}$ to make sure all ingot melted, adding zinc powder in design capacity, holding about $750^{\circ} \mathrm{C}$ and stirring for $15 \mathrm{~min}$, then injecting into the molten under protective atmosphere to pour into a plate alloy ingot[9].

$\mathrm{Zn}$ as a solute atoms has a greater degree in the solid solution of magnesium, and a strong solution strengthening capability. In addition, chemical reaction it is easy to take place between $\mathrm{Zn}$ and $\mathrm{Fe}$, $\mathrm{Ni}$ or other impurity elements to form compounds, reducing the number of anodes mesophase, helping to form passivation film on the surface, improving the corrosion resistance. 
Adding strontium element can reduce the size of the magnesium alloy dendrite grain refinement, reduce microscopic shrinkage and increase the density of the casting.

Mg-0.8wt\% Ca alloy. Pure Mg ingots were melted down at $650^{\circ} \mathrm{C}$. Then the melt was heated to $710^{\circ} \mathrm{C}$ and $\mathrm{Mg}-30 \% \mathrm{Ca}$ hardener was added in the required quantity in order to obtain the target alloy composition, $\mathrm{Mg}-0.8 \% \mathrm{Ca}[10]$.

$\mathrm{Mg}-0.8 \mathrm{wt} \% \mathrm{Ca}$ alloy can avoid stress shielding effect as the elastic modulus is very close to human bones. And the degradation behavior in vivo of it can avoid secondary damage caused by removal. $\mathrm{Mg}$ and $\mathrm{Ca}$ ions generated from the degradation of $\mathrm{Mg}$-Ca alloy can be absorbed by the human body and the excess part can be discharged through body fluids.

\section{Conclusion}

Though the research on magnesium and magnesium alloy as medical metal material has just started, the strengths and potential of magnesium and magnesium alloy as a new generation of existing metallic biomaterial products exhibited will definitely appeal more and more people's attention. Through deep understanding of the nature of magnesium and magnesium alloy corrosion and systematic study of the deposition process and the mechanism, we can believe that broad application of magnesium alloy as metallic implant materials will appear, promoting bio-materials industry and magnesium products industry in the near future.

\section{Acknowledgements}

This work is supported by the National Natural Science Foundation of China Grant No.514051955), A Project of Shandong Higher Educational Science and Technology Program (J13LB06) and the Development Program of Science and Technology of $\operatorname{Jinan}(201303069)$.

\section{References}

[1] Yunlan Liu, Progress in biomedical metallic materials, Transactions of Zhejiang Vocational and Technical College, 08 (2008) 47-50.

[2]Yufeng Zheng, Bin Liu, Xuenan Gu, Advances in medical biodegradable metal materials, Materials Review, 23(2009)1-6.

[3]Jiang Liu, Development and application of metallic materials for medical, Metallic Functional Materials, 14(2007)38-42.

[4]Ke Yang, Research and development of medical stainless steel, Materials China, 29(2010)1-10.

[5]Honggang Wang, Preparation and biocompatibility of medical nickel-free austenitic stainless steel with high nitrogen, Functional Materials, 18(2012)2483-2487.

[6]Xingzheng Zou, Hong Wang, Shiqing Zhang, et al., New medical nitrogen nickel-free stainless steel, Materials Review, 26(2012)254-257.

[7]Jing Li, Fabrication and properties of bomedical porous Ti-Ni(Nb) alloy, Central South University(2014).

[8]Legan Hou, Studies on the preparation and properties of porous Ti-based metallic materials for biomedical applications, Harbin Engineering University(2013).

[9]Shuhua Cai, Preparation of Mg-Zn-Sr biomaterials and Research for its performance, Central South University(2013).

[10]M. Salahshoor, Y.B. Guo, Machining characteristics of high speed dry milling of biodegradable 
Magnesium-Calcium alloy, Mechanical Engineering(2010). 